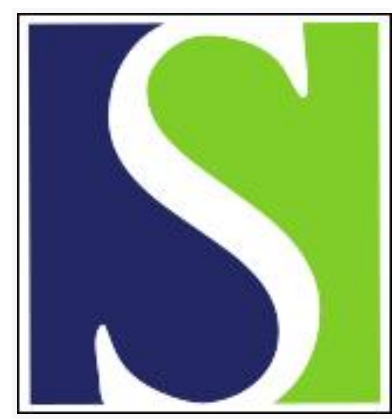

Scand J Work Environ Health 2008;34(1):55-65

https://doi.org/10.5271/sjweh.1192

Issue date: 29 Feb 2008

One-year randomized controlled trial with different physical-activity programs to reduce musculoskeletal symptoms in the neck and shoulders among office workers by Blangsted AK, Søgaard K, Hansen EA, Hannerz H, Sjøgaard G

Affiliation: National Research Centre for the Working Environment, Copenhagen, Denmark.

Refers to the following texts of the Journal: $2002 ; 28(2): 75-84 \quad 1997 ; 23$ suppl 1:49-57 2002;28(2):85-93 2004;30(5):399-409 2004;30(5):390-398 2003;29(3):197-205

The following articles refer to this text: $2009 ; 35(1): 1-5$; 2010;36(6):515-516; 2014;40(3):244-251; 2015;41(2):153-163; 2018;44(2):134-146; 2019;45(1):42-52; 2023;49(1):5-22

Key terms: musculoskeletal symptom; neck; office worker; physical training; physical-activity program; randomized controlled trial; resistance training; shoulder; sick leave; work ability; worksite 


\title{
One-year randomized controlled trial with different physical-activity programs to reduce musculoskeletal symptoms in the neck and shoulders among office workers
}

\author{
By Anne Katrine Blangsted, PhD, ${ }^{1}$ Karen Søgaard, PhD, ${ }^{1}$ Ernst A Hansen, PhD, ${ }^{2}$ Harald Hannerz, PhD, ${ }^{1}$ \\ Gisela Sjøgaard, DrMedSc ${ }^{1,3}$
}

\begin{abstract}
Blangsted AK, Søgaard K, Hansen EA, Hannerz H, Sjøgaard G. One-year randomized controlled trial with different physical-activity programs to reduce musculoskeletal symptoms in the neck and shoulders among office workers. Scand J Work Environ Health. 2008;34(1):55-65.
\end{abstract}

\begin{abstract}
Objectives This study evaluates the effect of two different worksite physical-activity interventions on neckshoulder symptoms, together with perceived work ability and sick leave among office workers.

Methods An examiner-blinded randomized controlled trial was conducted with 549 office workers allocated to one of three intervention groups: one with specific resistance training (SRT) of the neck-shoulder region $(\mathrm{N}=180)$, one with all-round physical exercise (APE) $(\mathrm{N}=187)$, and one which acted as a reference group, which was informed about general health-promoting activities but did not include a physical activity program $(\mathrm{N}=182)$. Questionnaires were filled out at baseline and after 1 year of training.

Results The duration and intensity of neck and shoulder symptoms was lower after the specified worksite physical-activity interventions than in the reference group. On an intervention group level, SRT was not more effective than APE in reducing the duration and intensity of neck and shoulder symptoms. However, those asymptomatic at baseline had a significant lower prevalence of neck-shoulder symptoms at follow-up when allocated to the SRT group than when placed in the APE group or reference group. At baseline the work ability index (WAI) was close to $90 \%$ of the maximum score, and the mean sick leave was 5 days per year, both being unaffected by the interventions.

Conclusions Different physical-activity interventions were successful in reducing neck-shoulder symptoms, and SRT was superior to APE in the primary prevention of such symptoms. The initially relatively high WAI was the most probable reason for no further increase in WAI. Likewise the mean sick leave the year before the intervention was very low, and it was probably not possible to reduce it further.
\end{abstract}

Key terms physical training; resistance training; sick leave; work ability; worksite.

Musculoskeletal symptoms are widespread among computer users with a high incidence of symptoms, especially in the neck-shoulder region, and the costs and impact on quality of life due to these symptoms are considerable (1-4). Occupational computer use has become increasingly common over the past few decades, in particular among office workers; and the widespread use of computers today, together with the high incidence of symptoms, demonstrates a potential for the prevention or alleviation of symptoms among, for example, office workers, through the use of targeted interventions.
A critical review concluded that worksite physicalactivity programs may have a positive effect on reducing musculoskeletal disorders (5). However, only a limited number of randomized controlled trails of high quality was identified regarding physical activity (6). To mention positive findings among office workers, a 10-week aerobic training program was found to have a significant effect on neck pain among employees in an insurance company (7). In addition, light resistance training on a daily basis at the worksite reduced the intensity of neck symptoms, but not shoulder symptoms, among office workers (8).

1 National Research Centre for the Working Environment, Copenhagen, Denmark.

2 Norwegian School of Sport Sciences, Oslo, Norway.

3 Institute of Sport Sciences and Clinical Biomechanics, University of Southern Denmark, Odense, Denmark.

Correspondence to: Gisela Sjøgaard, Institute of Sport Sciences and Clinical Biomechanics, University of Southern Denmark, Campusvej 55, DK-5230 Odense, Denmark. [E-mail: G.Sjogaard@health.sdu.dk] 
Due to a lack of reliable studies, there is especially conflicting evidence concerning the efficacy of exercise programs on outcomes of complaints from the neck and shoulder regions (9-11). This lack has led to repeated requests in the scientific literature for more randomized, controlled trails of high methodological quality.

In particular, evidence-based guidelines are still lacking on the type of physical exercise intervention that is most efficient in relieving musculoskeletal symptoms $(11,12)$. Only a few studies have compared different exercise programs. Among female industrial workers, 12 weeks of isometric endurance or strength training showed similar positive effects (13). Likewise, in a study among female office workers with chronic neck pain, both isometric strength training and dynamic endurance training effectively decreased pain and disability during a 1-year follow-up (14). However, aerobic and stretching exercises only, as performed by the control group, proved to be much less effective than strength training of the neck muscles. In contrast, a study including a similar group of persons did not find dynamic muscle training to be superior to relaxation training or ordinary activity (reference group) regarding neck pain at the 1-year follow-up (15). Of note is that the strength and endurance training protocols introduced in the aforementioned studies involved some similar aspects of neck-shoulder muscle loading and thus were not highly distinct from one another. Thus it remains unknown whether or not general fitness training may have a positive effect also on neck-shoulder pain.

Most of the studies in this area have included participants with neck-shoulder pain at entry into the intervention and thus studied rehabilitation or secondary prevention potentials. However, it seems even more pertinent to reveal the extent to which physical activity can play a role in the primary prevention of neck-shoulder symptoms among healthy workers. In addition, the potential of worksite physical-activity programs needs to be established not only for relieving pain, but also for improving work ability among employees needs. Inactivity is a major risk factor for adverse health effects-in particular in sedentary occupations such as office work, for which strenuous leisure-time physical activity may have beneficial health effects (16). Physical activity is one means of promoting individual resources and health status and thereby is a means of decreasing sick leave and improving work ability (17). However, evidence of the effectiveness of worksite physical-activity programs on perceived work ability is limited and has mainly focused on physically demanding jobs. A moderate physical-activity program once a week involving muscle strengthening, cardiovascular exercise, and stretching improved perceived work ability only slightly among women with physically demanding jobs (18). However, a 9-month supervised exercise intervention twice a week significantly improved the work ability of home care workers (19).

Based on the aforemenioned background, a randomized controlled trial was carried out to evaluate the effect of two highly different worksite physical-activity interventions on musculoskeletal symptoms in the neckshoulder region, together with perceived work ability and sick leave among office workers. More specifically, the study was designed to test the following hypotheses: (i) musculoskeletal symptoms in the neck-shoulder region among office workers can be reduced by specified worksite physical-activity interventions, (ii) specific resistance training of the neck-shoulder region is more effective than all-round physical exercise in reducing neck and shoulder symptoms (this results from a larger decrease in symptoms among those symptomatic at baseline, as well as less symptom development among those asymptomatic at baseline), (iii) work ability will increase and the sick leave rate will decrease as the prevalence of musculoskeletal symptoms decreases.

\section{Study population and methods}

\section{Study design}

A cluster randomized controlled trial was conducted. The participants were recruited from 12 geographically different units of a national Danish public administration authority located in the eastern part of Denmark. All of the participants worked in an office environment. The criteria for exclusion were (i) hypertension or cardiovascular diseases, (ii) symptomatic disc prolapses or severe disorders of the cervical spine, (iii) postoperative conditions in the neck and shoulder region, (iv) history of severe trauma, and (v) pregnancy. All of the participants gave their written consent before entering the study. The study protocol was approved by the local ethics committee (KF 01-201/04) and qualified for registration in the International Standard Randomised Controlled Trial Number Register on http://isrctn.org and has been assigned a unique trial identification number (ISRCTN31187106).

\section{Study population}

Altogether 2163 employees were invited to participate in the study. A short introduction and invitation text, together with a link to an Internet-based questionnaire-in four sections - on current health and symptoms were e-mailed to the prospective participants to examine their status regarding the exclusion criteria and to enable further selection. Out of the 2163 employees invited to participate, 1397 replied to the invitation, and 841 employees were 
willing to participate. There was no significant difference between the employees accepting and those declining participation with respect to gender, age, height, and body mass. However, the employees accepting participation had a higher 1-year prevalence of musculoskeletal symptoms in the neck and shoulders. The baseline characteristics of the two groups are presented in table 1.

Of the 841 employees accepting participation, 225 were excluded due to health risks or because too few at their unit wanted to participate. Therefore 3 of the 12 units were not offered any intervention. Thereby 616 participants were included in the study group at 9 units. There was no significant difference in the baseline characteristics between the participants included in the study $(\mathrm{N}=616)$ and the employees accepting participation ( $\mathrm{N}=841)$ (table 1). After the baseline measurements, an additional 24 participants were excluded due to health risks, and another 43 participants chose to withdraw from the study. The remaining 549 participants were randomly allocated to three intervention groups. A sample size of approximately 180 participants per intervention (allowing for a 10\% loss to follow-up) was needed for $80 \%$ power to detect a $10 \%$ change in muscle strength (20). With a $10 \%$ change in muscle strength, there was a high likelihood that there would be a detectable impact on musculoskeletal symptoms in the neck and shoulder area. After the cluster randomization, workers were excluded if they contracted a condition included in the aforementioned exclusion criteria or if they were on maternity leave or on other long-term absences (men and women).

\section{Randomization}

The employees who agreed to volunteer for the study were randomized into two different "physical-activity" groups and a "reference" group. A balanced cluster randomization was applied at the level of physical location of the participants at the worksite within each unit (21). Two to three types of intervention were conducted in each unit, one-third or two-thirds of the participants being allocated to each of the interventions (table 2). Clusters of participants were located on the same floor or in the same building and thus participated in the same intervention group. This approach was used to avoid contamination of the intervention and to enhance the compliance within the intervention groups, as well as to implement the study in a natural work environment. At the largest of the nine units, all three intervention groups were present, while only one of the physical-activity groups and a reference group were present at the remaining eight units. The distribution of the different intervention groups at the nine units and the number of participants in each group is presented in table 2, together with the number of clusters and the range of cluster size. Only nine "clusters" contained only a single individual.

Table 1. Baseline characteristics of the population that replied to the invitation for participation in the study, the population included in the study, and the three intervention groups (specific resistance training, all-round physical exercise, and reference).

\begin{tabular}{|c|c|c|c|c|c|c|c|c|c|c|}
\hline \multirow[t]{3}{*}{ Group } & \multirow[t]{3}{*}{ Gender (\%) } & \multicolumn{2}{|c|}{ Age (years) } & \multicolumn{2}{|c|}{ Height (m) } & \multicolumn{2}{|c|}{ Body mass $(\mathrm{kg})$} & \multicolumn{3}{|c|}{ One-year prevalence (\%) } \\
\hline & & \multirow[b]{2}{*}{ Mean } & \multirow[b]{2}{*}{$\mathrm{SD}$} & \multirow[b]{2}{*}{ Mean } & \multirow[b]{2}{*}{ SD } & \multirow[b]{2}{*}{ Mean } & \multirow[b]{2}{*}{$\mathrm{SD}$} & \multirow[t]{2}{*}{ Neck symptoms } & \multicolumn{2}{|c|}{ Shoulder symptoms } \\
\hline & & & & & & & & & $\begin{array}{c}\text { Left } \\
\text { shoulder }\end{array}$ & $\begin{array}{c}\text { Right } \\
\text { shoulder }\end{array}$ \\
\hline \multicolumn{11}{|c|}{ Accepted participation ( $\mathrm{N}=841$ ) } \\
\hline Men $(\mathrm{N}=303)$ & 35.9 & 47.1 & 9.2 & 1.81 & 0.07 & 84.1 & 13.0 & $65.8^{a}$ & 34.9 & $48.5^{\mathrm{a}}$ \\
\hline Women $(\mathrm{N}=538)$ & 64.1 & 45.5 & 9.5 & 1.68 & 0.06 & 69.0 & 12.6 & $85.7^{a}$ & $55.0^{a}$ & $69.0^{\mathrm{a}}$ \\
\hline \multicolumn{11}{|c|}{ Declined participation ( $\mathrm{N}=556)$} \\
\hline Men $(N=219)$ & 39.4 & 46.7 & 11.2 & 1.81 & 0.07 & 84.4 & 16.3 & 56.2 & 30.6 & 35.6 \\
\hline Women $(\mathrm{N}=337)$ & 60.6 & 46.4 & 10.3 & 1.68 & 0.06 & 67.6 & 13.4 & 78.6 & 41.5 & 56.7 \\
\hline \multicolumn{11}{|c|}{ Included in study population $(\mathrm{N}=616)$} \\
\hline Men $(\mathrm{N}=219)$ & 35.6 & 45.7 & 9.3 & 1.81 & 0.07 & 83.1 & 11.5 & 66.4 & 35.0 & 48.4 \\
\hline Women $(\mathrm{N}=397)$ & 64.4 & 44.6 & 9.5 & 1.68 & 0.06 & 68.2 & 12.0 & 84.6 & 52.6 & 66.8 \\
\hline \multicolumn{11}{|c|}{ Specific resistance training $(\mathrm{N}=180)$} \\
\hline Men $(N=54)$ & 30.0 & 47.3 & 9.3 & 1.81 & 0.06 & 82.5 & 8.6 & 55.8 & 28.8 & 46.2 \\
\hline Women $(\mathrm{N}=126)$ & 70.0 & 45.5 & 10.4 & 1.68 & 0.06 & 68.9 & 12.9 & 88.1 & 55.6 & 69.0 \\
\hline \multicolumn{11}{|c|}{ All-round physical exercise $(\mathrm{N}=187)$} \\
\hline Men $(\mathrm{N}=67)$ & 35.8 & 43.1 & 9.5 & 1.81 & 0.07 & 83.8 & 13.2 & 67.2 & 34.3 & 47.8 \\
\hline Women $(\mathrm{N}=120)$ & 64.2 & 44.4 & 8.0 & 1.67 & 0.06 & 66.2 & 10.4 & 80.0 & 50.8 & 67.5 \\
\hline \multicolumn{11}{|l|}{ Reference $(\mathrm{N}=182)$} \\
\hline Men $(\mathrm{N}=74)$ & 40.7 & 46.3 & 9.0 & 1.81 & 0.06 & 81.6 & 10.3 & 75.7 & 37.8 & 48.6 \\
\hline Women $(\mathrm{N}=108)$ & 59.3 & 43.9 & 9.7 & 1.69 & 0.06 & 70.4 & 12.6 & 85.2 & 47.2 & 64.8 \\
\hline
\end{tabular}

a The difference between the employees accepting participation and those declining participation was statistically significant. 
Table 2. Number of participants in the intervention groups within the nine geographically different units of the Danish public administrative authority for each of the three intervention groups (specific resistance training, all-round physical exercise, and reference). The number of clusters and the range of the cluster size are specified for each unit.

\begin{tabular}{|c|c|c|c|c|c|c|c|c|c|}
\hline \multirow[t]{3}{*}{ Unit } & \multicolumn{9}{|c|}{ Group } \\
\hline & \multicolumn{3}{|c|}{ Specific resistance training } & \multicolumn{3}{|c|}{ All-round physical exercise } & \multicolumn{3}{|c|}{ Reference } \\
\hline & $\begin{array}{l}\text { Participants } \\
\text { (N) }\end{array}$ & $\begin{array}{l}\text { Clusters } \\
\text { (N) }\end{array}$ & $\begin{array}{c}\text { Cluster size } \\
\text { (range) }\end{array}$ & $\begin{array}{l}\text { Participants } \\
\text { (N) }\end{array}$ & $\begin{array}{l}\text { Clusters } \\
\text { (N) }\end{array}$ & $\begin{array}{l}\text { Cluster size } \\
\text { (range) }\end{array}$ & $\begin{array}{l}\text { Participants } \\
\text { (N) }\end{array}$ & $\begin{array}{l}\text { Clusters } \\
\text { (N) }\end{array}$ & $\begin{array}{l}\text { Cluster size } \\
\text { (range) }\end{array}$ \\
\hline 1 & 70 & 8 & $1-18$ & 66 & 7 & $1-19$ & 83 & 15 & $1-11$ \\
\hline 2 & 30 & 2 & $5-25$ & . & . & $\cdot$ & 19 & 1 & 19 \\
\hline 3 & 24 & 6 & $1-7$ & . & . & . & 14 & 5 & $1-7$ \\
\hline 4 & 35 & 5 & $3-10$ & . & . & . & 12 & 3 & $1-7$ \\
\hline 5 & 21 & 3 & $2-13$ & . & . & . & 9 & 1 & 9 \\
\hline 6 & . & . & $\cdot$ & 30 & 3 & $7-13$ & 13 & 2 & $4-9$ \\
\hline 7 & . & . & . & 35 & 6 & $3-12$ & 7 & 2 & $1-6$ \\
\hline 8 & . & . & . & 22 & 2 & $7-15$ & 12 & 1 & 12 \\
\hline 9 & . & . & . & 34 & 4 & $1-17$ & 13 & 2 & $6-7$ \\
\hline Total & 180 & & & 187 & & & 182 & & \\
\hline
\end{tabular}

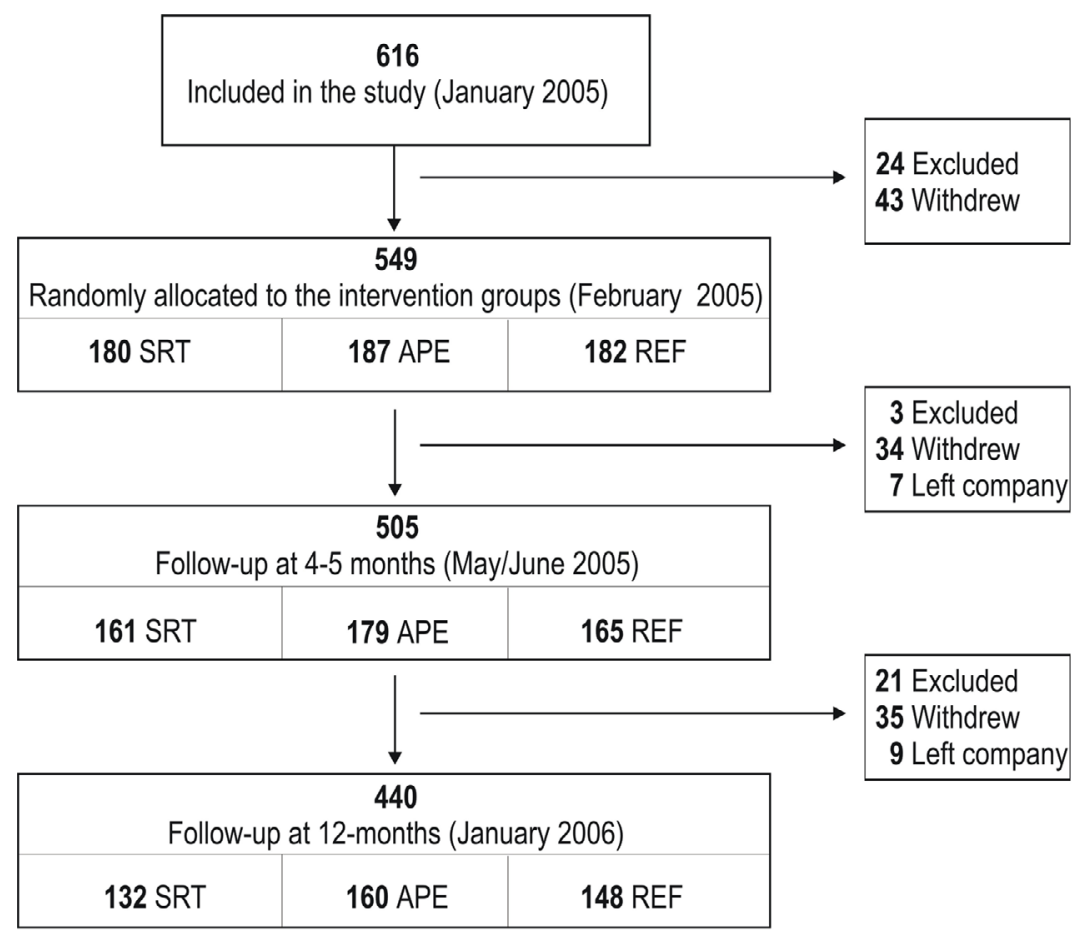

Figure 1. Flowchart showing the progress of the participants in the intervention groups during the study period. (SRT = specific resistance training, $\mathrm{APE}=$ all-round physical exercise, REF = reference group)
After the baseline measurements, the participants were assigned to a specific resistance training (SRT) group $(\mathrm{N}=180)$, an all-round physical exercise (APE) group ( $\mathrm{N}=187)$, or a reference group $(\mathrm{N}=182)$. A flowchart showing the allocation of the participants to the intervention groups and the subsequent dropout during the study period is presented in figure 1 .

\section{Intervention}

The intervention took place over a 12-month period (February 2005 until January 2006) with questionnaires sent out in January 2005 and February 2006. The participants in all three intervention groups were allowed to use 1 hour a week during workhours for intervention activities.

Specific resistance training. The specific resistance training consisted of resistance training exercises specifically for the muscles in the shoulder and neck region. The training regime consisted of three sessions per week, each lasting approximately 20 minutes. Two of the weekly sessions were supervised by an experienced instructor. 
The exercises were composed of dynamic resistance training for the arms and shoulders, static exercises for the neck, and explosive rowing and kayaking ergometer exercises for improving maximum dynamic strength in the shoulder area. The specific resistance training was performed with dumbbells and consisted of the following exercises: shoulder extension, shoulder abduction, shoulder abduction with special attention to the supraspinatus muscle, and shoulder lift. In general, $2-3$ sets of $10-15$ repetitions ( $10-15$ repetition maximum) of each exercise were performed in each session. In the first couple of weeks, the participants worked with loads corresponding to approximately $50 \%$ of their maximum in order to focus on technique, become habituated to training, and avoid injuries. Subsequently, they were encouraged to add to the load if they could perform more than 15 repetitions.

Static neck exercises were performed in a sitting position. An inelastic strap was connected to a scale that was either handheld or secured to a hook fixed to the wall. The strap was positioned around the head of the participants in a way that repetitions could be performed directly forward, sideways to the right and left, and directly backward (22). Each repetition lasted 5 seconds.

Ergometers were used for the rowing (Concept2, Inc, Morrisville, VT, USA) and kayaking (Dansprint, Vanløse, Denmark) exercises to increase explosive strength. The ergometers were equipped with displays that informed the participants about the mean power output in each bout. In this way, they could follow their progress in the training. A maximum of 10 all-out bouts, lasting 15-30 seconds, could be performed, either rowing or kayaking, in each session.

The participants were encouraged to keep a training diary. This diary helped the instructors in their training guidance and helped motivate the participants to comply with the rather monotonous training program.

All-round physical exercise. In this intervention group the participants were motivated to increase their daily physical activity both at their worksite and during their leisure time. The participants were introduced to the exercise activities by experienced instructors with pep talks, in which the participants had a scholarly, motivating, and humoristic introduction to the concept of daily physical activity. As part of motivating the participants, they made "a contract" in which they listed ways to include more physical activity in their daily lives. Subsequent to the introductory sessions, the frequency of visits from the instructors ranged from 1 to 4 times per month. The physical exercises introduced at the worksite consisted of a mixture of activities. Groups were organized for such activities as Nordic walking and running, and some participants were supplied with step counters. In addition, an 8-minute CD-based exercise program for aerobic fitness and general strength (but not specifically for the neck and shoulder area) was introduced to the participants. Exercise instruments such as steppers were placed at strategic places (eg, by the copying machine).

The participants were encouraged by two campaigns to bike to work and to increase their daily activity during their leisure time. This effort was promoted by giving the participants information on the location and opening hours of local sports clubs, fitness centers, and swimming pools. Most of the activities involved large muscle groups and resulted in cardiopulmonary loading, but not in neck-shoulder muscle strengthening in order to distinguish clearly between the two "physical-activity" interventions.

Reference group. The main purpose of the activities in the reference group was to ensure that the participants would receive attention similar to the two physicalactivity intervention groups but that they would not perform additional physical activity. The participants were introduced to the intervention by a presentation of previous projects in other companies in which researchers from the National Research Centre for the Working Environment (NRCWE), Denmark, in cooperation with managers and employees, had improved work conditions and occupational health. The participants were encouraged to form groups that would try to improve existing nonoptimal health and work conditions (eg, ergonomics, stress, work organization, indoor air, and food quality in the cafeteria of the company). The participants organized presentations about different health-promoting initiatives such as diet and health, stress and health, indoor climate, meditation, and relaxation. Staff from the NRCWE supported their work (eg, by helping to organize presentations by experts in the field).

\section{Baseline and follow-up outcome variables}

An internet-based questionnaire was used to gather data on the baseline and follow-up and to ensure examinerblinded data collection. The variables included gender, age, height, body mass, musculoskeletal symptoms in the neck and shoulders, and the work ability index. All in all, it was an extensive questionnaire that was divided into four sections, each of which could be replied to within less that 20 minutes.

Musculoskeletal symptoms. During the past 7 days and within the last 3 months, musculoskeletal symptoms were reported according to a modified version of the Nordic questionnaire on trouble (ache, pain, or discomfort) with the neck and shoulders (23). In addition, a question regarding the mean intensity of pain during the last 3 months was reported. The following questions 
were posed: (i) "Have you had trouble in your [body part] at any time during the last 7 days" (yes; no) for symptom status, (ii) "How many days have you had trouble in [body part] during the last three months?" (0 days; 1-7 days; 8-30 days; $>30$ days; everyday) for symptom duration, and (iii) "On average, how intense was your pain in [body part] during the last three months on a 0-9 scale?" (where 0 means no complaints and 9 means pain as bad as it can be) for symptom intensity. The questions were asked with [body part] replaced first by the neck, then by the left shoulder, and then by the right shoulder. Answers to the question that concerned symptom duration were recoded as follows: 0 days $=0,1-7$ days $=4$, $8-30$ days $=19,>30$ days $=60$, everyday $=90$.

Perceived work ability. The work ability index (24) was used to assess perceived work ability, except for the exclusion of one question regarding current diseases and injuries diagnosed by a physician. The index is a sum variable based on questions regarding (i) work ability compared with the person's lifetime best (on a scale of 0-10), (ii) work ability in relation to physical and mental job demands (on a scale of 2-10), (iii) estimation of work impairment due to diseases (on a scale of 1-6), (iv) sick leave during the past 3 months (on a scale of 1-5), (v) personal health-related prognosis of work ability 2 years from now (points of 1,4 , or 7), and (vi) mental resources (on a scale of 1-4). The final score in our study ranged from 6 to 42 (the higher the score, the better the work ability) as compared with the original work ability index, which had a score range of $7-49$. Of note is that the question on "sick leave during the last 12 months" in the original version was replaced by "sick leave during the last 3 months according to a personnel file" multiplied by 4 , in order to have sufficient time resolution for a 1-year intervention study. In addition, changes in the sick leave scores of the work ability index were tested separately in relation to the intervention groups. Finally, the total number of sick leave days during the last year, accumulated from all sick leave events before the intervention in the personnel file, was compared with the score during the last 3 months before the intervention multiplied by 4 .

\section{Statistical analysis}

We used SAS version 8 (SAS Inc, Gary, NC, USA) for the analysis of variance (ANOVA) to test the hypotheses regarding the intervention effect on work ability and a multivariate analysis of variance (MANOVA) to test the hypotheses regarding the intervention effect on the intensity and duration of symptoms in the neck and shoulders. All of the data in our paper were analyzed on an intention to treat basis. The following MANOVA were run for changes in the duration and intensity, respectively, of symptoms in the neck, left shoulder, and right shoulder as a function of the intervention category "physical activity" (SRT or APE) versus reference, and correspondingly SRT versus APE. We added cluster as a nested random effect to adjust for the clustered randomization. Pearson correlation coefficients were calculated for changes in symptoms (duration and intensity) pairwise between the neck, right shoulder, and left shoulder, as well as for the change in perceived work ability versus the change in each of the six symptom variables (duration and intensity separately for the three body parts). Furthermore, we looked at change in symptom status in terms of the proportions of the participants who changed to no symptoms at follow-up given symptoms at baseline and vice versa on the basis of the "7 days' trouble" (yes, no) question. The participants were defined as having symptoms if they had trouble in at least one of the three body parts (neck, left shoulder, right shoulder). P-values were obtained through the use of Fisher's exact test. In addition, Fisher's exact test was used to analyze changes in the sick leave scores as estimated by the work ability index. The statistical significance level was set to 0.05 . Tests of one-sided hypotheses were deemed significant if a two-sided P-value was less than 0.1. In all of the analyses, we tested for interactions between gender and type of intervention. In the presence of significant interaction effects, we stratified the analysis by gender. For the (M)ANOVA, the P-values were obtained through the use of F-tests.

\section{Results}

The baseline characteristics age, height, body mass, and the percentage of women were 46.0 years, 1.72 meters, 72.9 kilograms, and $70.0 \%$, respectively, for the SRT group; 43.9 years, 1.72 meters, 72.5 kilograms, and $64.2 \%$, respectively, for the APE group; and: 44.9 years, 1.73 meters, 75.0 kilograms, and $59.3 \%$, respectively, for the reference group. These data are presented separately for the women and men in table 1, together with the prevalence of neck and shoulder symptoms. No statistically significant differences were observed between the intervention groups at the baseline. The dropout over the first 4-5 months was $8.0 \%$, and for the full year it was $19.9 \%-26.6 \%$ from the SRT group, $14.4 \%$ from the APE group, and $18.7 \%$ from the reference group (figure 1). Incomplete questionnaire replies at baseline were found for two participants in the SRT group and for one participant in the reference group. In addition to the $\sim 20 \%$ dropout rate, incomplete questionnaire replies resulted in a total of $34.6 \%$ of the participants who answered the questionnaire at baseline being missing 
at the follow-up- $42.7 \%$ were missing from the SRT group (replies included from $\mathrm{N}=102$ ), 29.9\% from the APE group (replies included from $\mathrm{N}=131$ ), and $31.3 \%$ from the reference group (replies included from $\mathrm{N}=124$ ). Altogether, $54.2 \%$ of the participants who responded at the follow-up had neck or shoulder symptoms at baseline (54.9\% in the SRT group, 53.4\% in the APE group, and $54.5 \%$ in the reference group).

The correlation coefficients for change in the intensity of symptoms in the three body parts were $0.37(\mathrm{P}<0.0001)$ for the neck and left shoulder, 0.40 $(\mathrm{P}<0.0001)$ for the neck and right shoulder, and 0.35 $(\mathrm{P}<0.0001)$ for the left and right shoulders. The correlation coefficients for the change in the duration of symptoms were $0.29(\mathrm{P}<0.0001)$ for the neck and left shoulder, $0.44(\mathrm{P}<0.0001)$ for the neck and right shoulder, and $0.28(\mathrm{P}<0.0001)$ for the left and right shoulders.

In the MANOVA, there were statistically significant differences between those who performed "physical activity" and the reference group, both with regard to improvements in the intensity $(\mathrm{P}=0.0318)$ and the duration $(\mathrm{P}=0.0565)$ of symptoms according to tests of one-sided hypotheses since the P-values given are two-sided. There were no statistically significant effects from interaction between the body part and the intervention group ("physical-activity" groups versus reference group) $[\mathrm{P}($ intensity $)=0.4502 ; \mathrm{P}($ duration $)=0.1294]$, and there were no statistically significant differences between the outcomes in the two "physical-activity" groups (SRT versus $\mathrm{APE})[\mathrm{P}($ intensity $)=0.5327 ; \mathrm{P}($ duration $)=0.4016]$. There was no statistically significant interaction between gender and type of intervention- $\mathrm{P}$ (intensity $)=0.4783$; $\mathrm{P}($ duration $)=0.2568$. For each body part and intervention group, the mean duration and intensity of symptoms during the last 3 months prior to the baseline and the follow-up is given in figure 2 .

In the analysis of the proportions of participants asymptomatic at the baseline who had symptoms in the follow-up, we found a significant effect for interaction between gender and type of intervention $(\mathrm{P}=0.0130)$. This particular part of the analysis was therefore stratified by gender. Among the workers without symptoms

\section{Intensity of symptoms last three months}

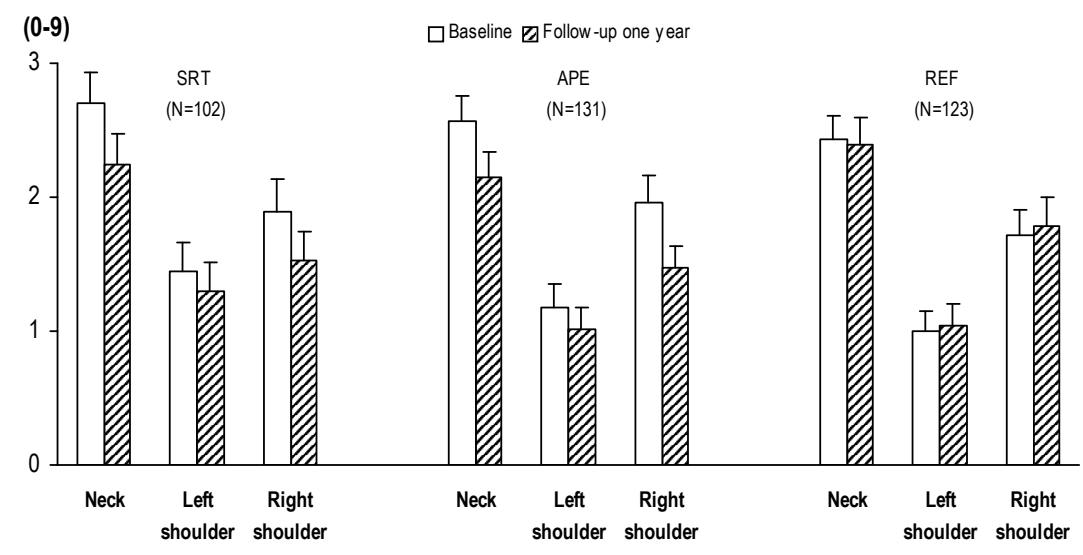

\section{Duration of symptoms last three months}

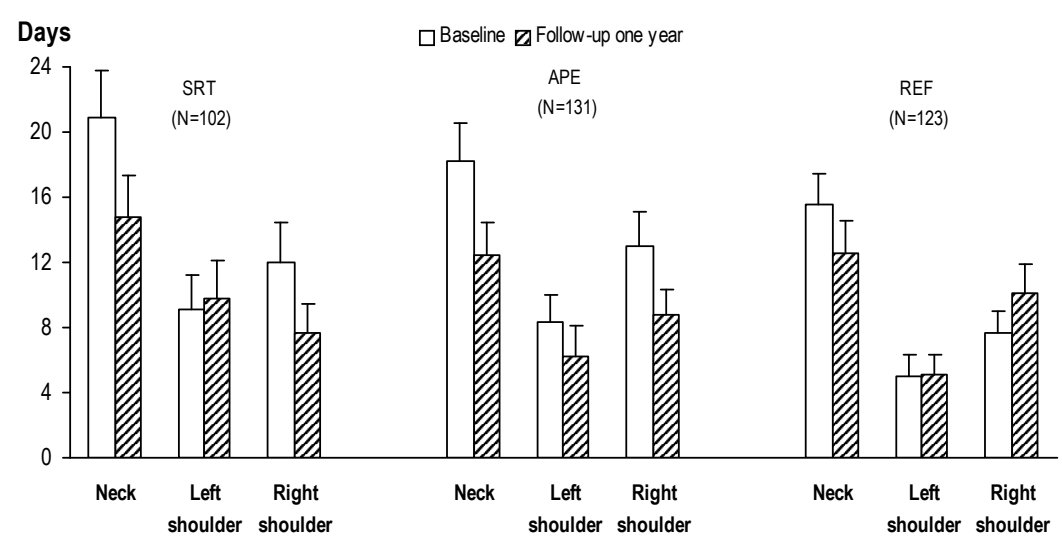

Figure 2. Mean (bars = $1 \mathrm{SE}$ ) intensity and duration of complaints at the baseline and follow-up, respectively, where $0=$ no complaints and $9=$ pain as bad as could be. (SRT = specific resistance training group, APE = all-round physical exercise group, REF = reference group) 
Table 3. Numbers of participants with neck or shoulder symptoms at the follow-up among the participants who did not have symptoms at the baseline and those who had symptoms at the baseline for each of the three intervention groups.

\begin{tabular}{|c|c|c|c|c|c|c|c|c|c|c|c|c|}
\hline \multirow[t]{4}{*}{ Intervention group } & \multicolumn{6}{|c|}{ Participants with no symptoms at baseline } & \multicolumn{6}{|c|}{ Participants with symptoms at baseline } \\
\hline & \multicolumn{3}{|c|}{ Women } & \multicolumn{3}{|c|}{ Men } & \multicolumn{3}{|c|}{ Women } & \multicolumn{3}{|c|}{ Men } \\
\hline & \multirow[t]{2}{*}{$\begin{array}{l}\text { At base- } \\
\text { line (N) }\end{array}$} & \multicolumn{2}{|c|}{$\begin{array}{c}\text { At } \\
\text { follow-up }\end{array}$} & \multirow[t]{2}{*}{$\begin{array}{l}\text { At base- } \\
\text { line (N) }\end{array}$} & \multicolumn{2}{|c|}{$\begin{array}{c}\text { At } \\
\text { follow-up }\end{array}$} & \multirow[t]{2}{*}{$\begin{array}{l}\text { At base- } \\
\text { line (N) }\end{array}$} & \multicolumn{2}{|c|}{$\begin{array}{c}\text { At } \\
\text { follow-up }\end{array}$} & \multirow[t]{2}{*}{$\begin{array}{l}\text { At base- } \\
\text { line (N) }\end{array}$} & \multicolumn{2}{|c|}{$\begin{array}{c}\text { At } \\
\text { follow-up }\end{array}$} \\
\hline & & N & $\%{ }^{a}$ & & N & $\%^{a}$ & & N & $\%^{a}$ & & N & $\%^{\mathrm{a}}$ \\
\hline Specific resistance training & 28 & 5 & 17.9 & 18 & 1 & 5.6 & 48 & 36 & 75.0 & 8 & 5 & 62.5 \\
\hline All-round physical exercise & 31 & 8 & 25.8 & 30 & 13 & 43.3 & 50 & 35 & 70.0 & 20 & 10 & 50.0 \\
\hline Reference & 25 & 12 & 48.0 & 31 & 4 & 12.9 & 43 & 32 & 74.4 & 24 & 15 & 62.5 \\
\hline
\end{tabular}

a Percentage of the number at baseline.

Table 4. Mean and standard error (SE) of the work ability index according to gender for each of the three intervention groups ( maximum score $=42$ ).

\begin{tabular}{|c|c|c|c|c|c|c|c|c|}
\hline \multirow[t]{3}{*}{ Intervention group } & \multicolumn{4}{|c|}{ Women } & \multicolumn{4}{|c|}{ Men } \\
\hline & \multicolumn{2}{|c|}{ Baseline } & \multicolumn{2}{|c|}{ Follow-up } & \multicolumn{2}{|c|}{ Baseline } & \multicolumn{2}{|c|}{ Follow-up } \\
\hline & Mean & SE & Mean & SE & Mean & SE & Mean & SE \\
\hline $\begin{array}{l}\text { Specific resistance } \\
\text { training }\end{array}$ & 37.4 & 0.37 & 36.9 & 0.42 & 37.7 & 0.54 & 38.0 & 0.49 \\
\hline $\begin{array}{l}\text { All-round physical } \\
\text { exercise }\end{array}$ & 37.1 & 0.32 & 36.6 & 0.39 & 37.4 & 0.37 & 36.8 & 0.66 \\
\hline Reference & 36.7 & 0.40 & 36.5 & 0.48 & 37.1 & 0.42 & 37.2 & 0.35 \\
\hline
\end{tabular}

at the baseline, we found a statistically significant intervention effect both for the women $(\mathrm{P}=0.0472)$ and for the men $(\mathrm{P}=0.0032)$ (table 3$)$. A pairwise comparison of the intervention groups using Fisher's exact test showed statistically significantly less development of symptoms among the women in the SRT group than in the reference group. Correspondingly, statistically significantly less development of symptoms was found among the men in the SRT group than among those in the APE group. Among the participants who had symptoms at baseline, there was no statistically significant intervention effect $(\mathrm{P}=0.8641$ for the women and $\mathrm{P}=0.6959$ for the men) (table 3 ).

The mean scores of the work ability index at the time of the baseline and follow-up are given in table 4 according to gender and type of intervention. As regards the change in the work ability index, there was no statistically significant interaction between gender and type of intervention $(\mathrm{P}=0.9201$ in the "physical-activity" versus reference analysis; $\mathrm{P}=0.3888$ in the "SRT" versus "APE" analysis). The changes in the work ability index were statistically independent of the type of intervention [P ("physical activity" versus reference) $=$ $0.3073, \mathrm{P}(\mathrm{SRT}$ versus APE $)=0.4220]$. There were no statistically significant correlations between the change in work ability and the change in symptom duration or intensity for any of the body parts. At the baseline, the participants' average sick leave during the last 3 months was 1.5 days, and the average sick leave during the preceding year was 5.3 days, the latter not being statistically significantly different from the 3 -month value multiplied by 4 . There were no statistically significant changes in the sick leave scores according to the type of intervention during the last 3 months $(\mathrm{P}=0.45)$.

\section{Discussion}

The major finding of this study was the confirmation of hypothesis 1 . The duration and intensity of neck and shoulder musculoskeletal symptoms among office workers was reduced by specified worksite physical-activity interventions when the results were compared with those of the reference intervention (general health-promoting activities not including physical activity). A major effort in this study was the implementation of interventions since previous studies have shown that merely advising people to participate in more exercise is ineffective (25) and a worksite rather than a primary care (or general practice) setting is more effective (26). The lack of an intervention effect may also be due to the profile of the physical-activity program being insufficient in terms of the intensity or frequency of repetition $(15,27)$. Finally, the mode or pattern of the physical-activity programs is crucial, since not all physical activity is beneficial. For example, occupational physical activity involving heavy manual materials handling or other physically heavy job tasks does not improve physical fitness (28) and may, on the contrary, deteriorate health (29). Our study confirmed that qualified and repeated instructions for physical activities established to have a training effect according to the physiological literature are also beneficial for reducing neck-shoulder symptoms (13, 14). The physiological training effects in our study re- 
main to be reported in forthcoming papers. The choice of implementation at the worksite proved to be successful in our study, possibly due to the convenience of getting in contact with the workers at the worksite, including those who did not have complaints at the baseline. This approach seems to be the most efficient way to conduct primary prevention. However, the effectiveness may be potentiated if action is taken also to promote lifestyle changes to additionally perform more vigorous activities during leisure time $(16,26)$, and counseling on physical activity at the worksite has been found to have a positive effect and should, therefore, be promoted (30).

Regarding guidelines on the type of physical-activity intervention that is most efficient in relieving musculoskeletal symptoms in the neck-shoulder region, our hypothesis 2 was only partially confirmative. Musclespecific resistance training of the neck-shoulder region was overall not more effective than all-round physical exercise in reducing the duration and intensity of neck and shoulder symptoms. This finding is in line with those of other studies that failed to demonstrate different effectiveness regarding neck and shoulder pain in different training programs $(13,14)$. However, one earlier study showed that the "rating of perceived exertion on the job" decreased significantly more after strength training than after endurance training in spite of the fact that the rating "worst pain during the last week" on a visual analogue scale decreased similarly in both groups (13). A general concern is that the trials conducted may not have had sufficient power to be conclusive. In addition, in our study, there was limited statistical power for testing whether or not the SRT was more effective than the APE in reducing musculoskeletal symptoms. Even if the odds for improvement or the prevention of neck and shoulder symptoms had been twice as high among the participants in the SRT group than in the APE group, the design of our study had only a $60 \%$ chance of detecting a difference because of the small sample size in the different groups, as seen in table 3 . The small sample sizes were due the $20 \%$ dropout and another $15 \%$ who did not reply to the follow-up questionnaire, a value much higher than the anticipated 10\% loss at follow-up. In addition, the separation by gender, as well as according to the presence of symptoms at baseline, resulted in very small groups. In our study, more specifically, $50-75 \%$ of those symptomatic at the baseline also reported symptoms at the follow-up, and therefore there was no significant difference between the intervention groups, a finding corresponding to earlier findings in chronic neck cases (15). However, those asymptomatic at the baseline had the lowest prevalence of neck-shoulder symptoms (the last 7 days) at the follow-up when allocated to the SRT group, both for the men and the women. This is a new finding, and it underlines the importance of studying primary prevention.
The transfer effect of decreased neck-shoulder symptoms resulting in increased work ability and decreased sick leave was tested in our third hypothesis, but the result was rejection. The work ability index did not increase, and sick leave did not decrease in the interventions that reduced the duration and intensity of musculoskeletal symptoms. In a previous study, physical activity was shown to have a positive effect on sick leave, and a significant relationship was found between exercise frequency and illness-related absenteeism (31). Furthermore, workers with a vigorous intensity level of at least three times a week had significantly fewer sick leaves of $>4$ days per year, while moderate physical activity was unrelated to sick leave (32). Likewise, strenuous leisure-time activity 1-2 times a week was associated with a lower risk of long-term absenteeism (16). In contrast, a study in which exercise intervention was introduced with light aerobic exercise, muscle strengthening and stretching had no positive effect on sick leave in a comparison with a control group (27). Another intervention study implementing a more-intense training program that improved muscle pain also showed no decrease in absenteeism (33). A review paper concluded that the evidence of the effect of physical-activity programs at worksites was limited for absenteeism (34). Our intervention probably did not sufficiently meet the vigorous intensity level or frequency that would result in a positive effect on changed overall physical activity and may therefore have not been effective regarding sick leave. More importantly, however, the workers in our study had a low sick leave rate at the baseline (5 days per year) due to a special program run at the company to reduce sick leave per se. Therefore, the average number of sick leave days during the last 3 months was unlikely to decrease significantly, as a magnitude of a 4-day decrease would have probably been needed for the study to have sufficient power to demonstrate statistical changes on a yearly basis. For the same reason, probably no significant correlations were found between the change in the work ability index and the change in symptoms in the neck-shoulder region. At the baseline, the perceived work ability was close to $90 \%$ of the maximum score, and this relatively high value was the most probable reason for no further increase in perceived work ability.

The strength of our study is its rigorous design, which complied with the criteria for randomized controlled trails that have been requested by several review papers $(5,6)$. In addition, an extension to cluster randomization was made to minimize contamination (21). Finally, the intervention took place over a full year; thus the questionnaire replies were from the same time of the year, and therefore seasonal variation that might have biased the results was eliminated. Interestingly, even the sick leave score during the last 3 months was representative for the whole year, since no statistically 
significant differences were found between sick leave recorded over a full year and that recorded for the 3 months used in the study multiplied by 4 for the year 2004. However, obviously the study also encountered several difficulties. These difficulties resulted in a number of weaknesses in the dataset obtained in the study. An obvious weakness was the combined dropout ( 20\%) and incomplete questionnaire replies $(\sim 15 \%)$, which was much larger than anticipated in spite of many actions being taken. The high number of incomplete replies to the Internet-based questionnaire was due to the division of the questionnaire into four sections that could be answered separately. This procedure was used because the employer requested that the workers not interrupt their work for more than 20 minutes at a time when replying to the questionnaire. Unfortunately, a significant number answered only $1-3$ of the set of 4 in spite of two reminders. Another weakness is related to the participants' adherence to the intervention activities. The instructors and lecturers were aware of this condition, and they personally contacted those who did not participate regularly. Furthermore, e-mails were sent regularly from the research team to keep the participants motivated, and the research team contacted the representatives and leadership of the company several times. There is no simple solution, and high adherence is considered to be the largest challenge in physical-activity intervention studies. The questionnaire contained questions on compliance in May and June 2005 and in January 2006, and these findings will be presented in a separate paper. In addition to the present intention-to-treat analysis, a per-protocol analysis has been planned but has not yet been carried out. It should also be pointed out that no neutral control group was included. In worksite studies, a neutral control group is probably not an option. If no activities are offered to the participants in the control groups, they may be very negative in answering questionnaires when they learn about the activities offered to the intervention groups, and this possibility may bias the outcome of the control group. Furthermore, in this study, we decided to reveal the effect of physical activity separately from, or in addition to, the affect of giving more attention to the workers' well-being. We, therefore, planned from the beginning that we would not have a neutral control group but, instead, would include a reference group that was given as much attention as the physical-activity groups. Finally, considerations of the statistics resulted in applying (M)ANOVA. This approach was justified since we tested changes in all of the outcome variables, and the distributions became symmetric, and, due to the way the survey was designed, there were no extreme outliers that could slow the convergence process. Moreover, there were more than 100 participants in each group. Hence we assumed that we could test our outcomes as if they were normally distributed. We performed a Monte-
Carlo simulation that verified that this assumption was reasonable. However, the subgroups of the cases and referents at baseline became so small when divided by gender that we had to apply exact methods. Interestingly, statistically significant differences were found, although the large confidence intervals emphasize the low predictive value.

In conclusion, the major finding of our study was a significant reduction in the duration and intensity of neck and shoulder musculoskeletal symptoms among the office workers during a 1-year intervention using worksite physical-activity programs. Furthermore, specific resistance training was more effective in preventing the development of neck-shoulder symptoms among those asymptomatic at baseline than all-round physical exercise was. At baseline, among the office workers, the work ability index was close to $90 \%$ of the maximum score, sick leave had a mean of only 5 days for the preceding year, and neither changed significantly within any of the interventions groups. It is recommended that various modes of worksite physical-activity programs that appear attractive to workers be promoted to stimulate participation and prevent dropout. Care must be taken to see that the participants train at a sufficiently high intensity and frequency with exercise programs relevant with respect to their occupational load to gain optimal beneficial effects on musculoskeletal symptoms.

\section{Acknowledgments}

The study was financially supported by funding from the Ministry of Culture Committee on Sports Research N200310016 and the National Board of Health under the Ministry of the Interior and Health.

The contribution in terms of manpower allowing 600 employees to train during worktime for 1 hour per week for 1 year was given by the workplace involved. The training was supervised by Dansk Firmaidrætsforbund (DFIF) regarding the all-round physical exercise and by Mogens Theisen Pedersen at the Department of Exercise and Sport Sciences, University of Copenhagen, regarding the specific resistance training. For excellent technical support, we want to thank technician Dorte Ekner and physiotherapist Klaus Hansen.

\section{References}

1. Jensen C. Development of neck and hand-wrist symptoms in relation to duration of computer use at work. Scand J Work Environ Health. 2003;29(3):197-205.

2. Juul-Kristensen B, Søgaard K, Strøyer J, Jensen C. Computer users' risk factors for developing shoulder, elbow and back 
symptoms. Scand J Work Environ Health. 2004;30(5):390-8.

3. Brandt LP, Andersen JH, Lassen CF, Kryger A, Overgaard E, Vilstrup I, et al. Neck and shoulder symptoms and disorders among Danish computer workers. Scand J Work Environ Health. 2004;30(5):399-409.

4. Gerr F, Monteilh CP, Marcus M. Keyboard use and musculoskeletal outcomes among computer users. J Occup Rehabil. 2006;16:265-77.

5. Proper KI, Koning M, van der Beek AJ, Hildebrandt VH, Bosscher RJ, van Mechelen W. The effectiveness of worksite physical activity programs on physical activity, physical fitness, and health. Clin J Sport Med. 2003;13(2):106-17.

6. Brewer S, Van Eerd D, Amick BCI, Irvin E, Daum KM, Gerr $\mathrm{F}$, et al. Workplace interventions to prevent musculoskeletal and visual symptoms and disorders among computer users: a systematic review. J Occup Rehabil. 2006;16(3):325-58.

7. Groenningsaetter H, Hytten K, Skauli G, Christensen CC, Ursin H. Improved health and coping by physical exercise or cognitive behavioral stress management training in a work environment. Psychol Health. 1992;7:147-63.

8. Sjögren T, Nissinen KJ, Järvenpää SK, Ojanen MT, Vanharanta H, Mälkiä EA. Effects of a workplace physical exercise intervention on the intensity of headache and neck and shoulder symptoms and upper extremity muscular strength of office workers: a cluster randomized controlled cross-over trial. Pain. 2005;116:119-28.

9. Verhagen AP, Karels C, Bierma-Zeinstra SM, Feleus A, Dahaghin S, Burdorf A, et al. Exercise proves effective in a systematic review of work-related complaints of the arm, neck, or shoulder. J Clin Epidemiol. 2007;60(2):110-7.

10. Silverstein B, Clark R. Interventions to reduce work-related musculoskeletal disorders. J Electromyogr Kinesiol. 2004; 14(1):135-52.

11. Mior S. Exercise in the treatment of chronic pain. Clin J Pain. 2001;17(4 Suppl):S77-S85.

12. Ylinen JJ, Häkkinen AH, Takala EP, Nykänen MJ, Kautiainen HJ, Mälkiä EA, et al. Effects of neck muscle training in women with chronic neck pain: one-year follow-up study. J Strength Cond Res. 2006;20(1):6-13.

13. Hagberg M, Harms-Rimgdahl K, Nisell R, Hjelm EW. Rehabilitation of neck-shoulder pain in women industrial workers: a randomized trial comparing isometric shoulder endurance training with isometric shoulder strength training. Arch Phys Med Rehabil. 2000;81(August):1051-8.

14. Ylinen J, Takala EP, Nykänen M, Häkkinen A, Mälkiä E, Pohjolainen $\mathrm{T}$, et al. Active neck muscle training in the treatment of chronic neck pain in women: a randomized controlled trial. JAMA. 2003;289(19):2509-16.

15. Viljanen M, Malmivaara A, Uitti J, Rinne M, Palmroos P, Laippala P. Effectiveness of dynamic muscle training, relaxation training, or ordinary activity for chronic neck pain: randomised controlled trial. BMJ. 2003;327(7413):475.

16. Bernaards CM, Jans MP, Van den Heuvel SG, Hendriksen IJ, Houtman IL, Bongers PM. Can strenuous leisure time physical activity prevent psychological complaints in a working population? Occup Environ Med. 2005;63:10-6.

17. Ilmarinen J, Rantanen J. Promotion of work ability during ageing. Am J Ind Med. 1999;(suppl)1:21-3.

18. Nurminen E, Malmivaara A, Ilmarinen J, Ylöstalo P, Mutanen P, Ahonen G, et al. Effectiveness of a worksite exercise program with respect to perceived work ability and sick leaves among women with physical work. Scand J Work Environ
Health. 2002;28(2):85-93.

19. Pohjonen T, Ranta R. Effects of worksite physical exercise intervention on physical fitness, perceived health status, and work ability among home care workers: five-year follow-up. Prev Med. 2001;32(6):465-75.

20. Sjøgaard G, Kiens B, Jørgensen K, Saltin B. Intramuscular pressure, EMG and blood flow during low-level prolonged static contraction in man. Acta Physiol Scand. 1986;128:47584.

21. Campbell MK, Elbourne DR, Altman DG. CONSORT statement: extension to cluster randomised trials. BMJ. 2004;328(7441):702-8.

22. Ylinen J, Ruuska J. Clinical use of neck isometric strength measurement in rehabilitation. Arch Phys Med Rehabil. 1994;75(4):465-9.

23. Kuorinka I, Jonsson B, Kilbom A, Vinterberg H, Biering-S $\varnothing$ rensen F, Andersson G, et al. Standardised Nordic questionnaires for the analysis of musculoskeletal symptoms. Appl Ergon. 1987;18(3):233-7.

24. Ilmarinen J, Tuomi K, Klockars M. Changes in the work ability of active employees over an 11-year period. Scand J Work Environ Health. 1997;23 suppl 1:49-57.

25. Hillsdon M, Thorogood M, White I, Foster C. Advising people to take more exercise is ineffective: a randomized controlled trial of physical activity promotion in primary care. Int J Epidemiol. 2002;31(4):808-15.

26. Proper KI, Heymans MW, Chin A Paw MJM, van Sluijs EMF, van Poppel MNM, van Mechelen W. Promoting physical activity with people in different places - a Dutch perspective. J Sci Med Sports. 2006;9(5):371-7.

27. Brox JI, Frøystein O. Health-related quality of life and sickness absence in community nursing home employees: randomized controlled trial pf physical exercise. Occup Med. 2005;55:55863.

28. Ruzic L, Heimer S, Misigoj-Durakovic M, Matkovic BR. Increased occupational physical activity does not improve physical fitness. Occup Environ Med. 2003;2003(60):983-5.

29. Savinainen M, Nygård CH, Ilmarinen J. A 16-year follow-up study of physical capacity in relation to perceived workload among ageing employees. Ergonomics. 2004;47(10):1087102.

30. Proper KI, Hildebrandt VH, van der Beek A, Twisk JWR, van Mechelen W. Effect of individual counseling on physical activity fitness and health: a randomized controlled trial in a workplace setting. Am J Prev Med. 2003;24(3):218-26.

31. Jacobson BH, Aldana SG. Relationship between frequency of aerobic activity and illness-related absenteeism in a large employee sample. J Occup Environ Med. 2001;43(12):1019-25.

32. Proper KI, Van den Heuvel SG, De Vroome EM, Hildebrandt VH, van der Beek AJ. Dose-response relation between physical activity and sick leave. Br J Sports Med. 2006;40:173-8.

33. Eriksen HR, Ihlebaek C, Mikkelsen A, Gronningsaeter H, Sandal GM, Ursin H. Improving subjective health at the worksite: a randomized controlled trial of stress management training, physical exercise and an integrated health programme. Occup Med (Lond). 2002;52(7):383-91.

34. Proper KI, Staal BJ, Hildebrandt VH, van der Beek AJ, van Mechelen W. Effectiveness of physical activity programs at worksites with respect to work-related outcomes [review]. Scand J Work Environ Health. 2002;28(2):75-84.

Received for publication: 30 may 2007 